\title{
One's Own Inner Peace Makes the World Peace
}

\author{
V. Lalithendra Nadh and J. V. Manoj
}

\begin{abstract}
In this paper we would like to discuss how "One's own inner peace leads to world peace" with the help of vegetarian food \& meditation. In present generation everyone thinks for world peace. Prior to that, we should be peaceful. If we exist then this earth exists. There was a saying in Telugu language which means "A country is not made of land; a country is made of its people". If we exist, this earth exists. We are all biological parts of this earth. We are in no way separated from it, from our mother. Even after our death, it gets us deposited back in to the ground. So if we are peaceful, this earth is peaceful. When we sit alone for some time \& observe our thoughts (the hell traffic of thoughts) we get to know/understand how peaceful we are. Are we? Meditation helps us in getting more clarity on this. That's where we come to conclusion that I myself am not peaceful. Main reason for not being peaceful is food. (We are what we eat).
\end{abstract}

Index Terms-Vegetarianism, ana panasathi meditation, brain waves, compassion, inner peace, world peace.

\section{INTRODUCTION}

Let us take few conditions that a human is currently facing in this world. It could be natural calamities, women harassment, inter country/state conflicts, robberies, fear; due to distrust on another human. I strongly believe that all these are happening because of human thoughts. Most of us spoke about 2012 world end. Most of us watched 2012 movie as well. Out of all who thought \& spoke about 2012, large amount of us thought about 2012 negatively. We are not even able to think something good or positive about our future. Daily incidents caused by us or by our fellow humans making us loose trust on future of this world. In fact many disastrous natural calamities this earth has seen after 2012 which are possible impacts of our negative thoughts.

\section{List of NAtURAl CALAmities/Wars/Conflicts AFter 2012}

2012 was the year of recurring disasters which nearly cost $\$ 160$ bn.

1) HurricaneSandy - New York (USA)

2) CycloneNilam - Tamil Nadu (India)

3) Philippinestyphoon

4) Indonesia earthquake (7.1 magnitude earthquake)

5) Myanmarearthquake

6) Uttarakashi flash flood

7) Iran earthquake - Twin earth quakes (1st one 6.4 magnitude \& second one at 6.3 magnitude)

Manuscript received November 10, 2013; revised January 21, 2014.

V. Lalithendra Nadh and J. V. Manojare with PSS Movement Org, CO 500081, India (e-mail: manoj.leverage@gmail.com, lalithvenigalla@gmail.com).
8) Assamfloods (17.60 million people affected)

9) Beijing flash flood (average of $1700 \mathrm{~mm}$ rain \& $450 \mathrm{~mm}$ in Fangshan district, the most heavily affected area located at south west)

10)Pakistan flood.

\section{How Thoughts ARe ReSPonsible For NATURAL CALAMITIES?}

When one feels superior, he starts commanding on his inferiors which leads to the suffering of many, and also, can lead to wars.

When one feels greedy, he will not be satisfied with what he need. And fights for what he wants.

Example: deforestation - leading to eco system imbalance (global warming)

Mining's more than our necessity causing earthquakes.

Weapons used in wars - loss of soil fertility, impact which lasted for decades, even centuries (diseases). Hiroshima Nagasaki is one important example for this.

Ocean wars, Oil spills -because of which crore's of fishes dying which in turn disturbs eco system leading to Tsunami's, Hurricanes, and Tornados.

We are not able to attain zero poverty for people on this earth \& dying out to find life on another planet.

As per Indian spirituality, there are 3 categories of thinking in people

\section{A. Sathvikas}

Those people who think always positive $\&$ are confident enough that they can achieve what they have been seeking for. People who at tough situations, will have a smile on their face $\&$ guide others towards their win with the experience these people have gathered in earlier situations that occurred in their life \& always wholeheartedly seek for others good as well.

\section{B. Rajasikas}

People who doesn't believe in themselves \& falls into depression thinking that they cannot win, who thinks they don't have the required capability, who don't even try.

\section{Thamasikas}

These are people who erect barricades to others growth. They cannot see others win even if it is not beneficiary to them. They always want to spoil others surroundings, situations, opportunities \& live with that satisfied egoistic minds.

This makes us think why different people have different types of thoughts. One of the main reasons for this is food. Yes, we are what we eat.

Thoughts depend up on what food we eat. There are different types of diet like Non-Vegetarians, Vegetarians, 
Fruitarians, Vegans. Flesh blood intensifies all the undesirable elements and passions of the lower planes.

Nowadays many of us prefer to become vegetarians as we are becoming more conscious towards health. Eating meat makes us strong is a wrong belief. The domestic animals have grown up by eating plant based food \& that's how their meat got good amount of protein. We do get the same protein food if we eat plant based food. Why to eat dead protein when we get the same protein fresh? Do we need to eat what is already chewed, digested, formed \& deposited in someone else's body? Or do we prefer to eat something that is always freshly available for us? Obviously we go for fresh ones. A little bit of awareness makes we go towards it. Food makes a big impact on our thoughts. Eating meat is violence. Doing meditation is for seeking peace. Violence \& peace are two opposite directions. How one eating meat can progress in spirituality to reach higher levels of consciousness? One has to adapt to vegetarianism which builds up compassion towards animals \& it acts as a catalyst for spiritual progress through meditation. Meat brings out negative qualities such as fear, anger, anxiety, aggressiveness, etc.

Carlos Santana, Musician said "Vegetables peacefully offer themselves to the earth when ripe, thus allowing a sublime and peaceful thought-consciousness."

Arthur E. Powell of the Theosophical Society has beautifully said the following:

"A physical body nourished on impure food will produce a correspondingly impure astral body, whilst a physical body fed on clean food and drink will help to purify the astral vehicle."

"It is impossible to make the physical body coarse and at the same time to organize the astral and mental bodies for finer purposes ... neither is it possible to have a pure physical body with impure mental and astral bodies. All three bodies are thus inter-dependent. "

"Carnivorous diet is fatal to anything like real occult development, and those who adopt it are throwing serious and unnecessary difficulties in their own way, for flesh blood intensifies all the undesirable elements and passions of the lower planes. "

Quantum vibrational science is recognizing the ill effects of animal food in human systems. Dr. James Hansen, Top world climatologist Director, NASA said that "An individual's contribution to reduce carbon emissions is shifting to plant based diet". "If you eat further down on the food chain rather than animals, which have produced many greenhouse gases, and used much energy in the process of growing that meat, you can actually make a bigger contribution in that way than just about anything. So that, in terms of individual action, is perhaps the best thing you can do."

In all religions, love is the main principle that has been taught, how come we can be violent towards animals for our appetite?

Ref. [1] recently we have also heard about a person named Joe who was $140 \mathrm{~kg}$ 's. No tablets worked for him to get reduced $\&$ the only way he can survive is by reducing his weight. Only vegetarian (plant based diet) helped him in reducing his weight \& survive. He also has taken a documentary on his journey "Fat, Sick \& Nearly Dead".
Ref. [2] purity is very important in our spiritual life. We must establish purity in the physical, the vital and the mind. The mild qualities of vegetables help us to establish the qualities of sweetness, softness, simplicity and purity in our inner life, as well as in our outer life.

The same thing was being conveyed by many great people to this world. We heard Einstein saying

"It is my view that the vegetarian manner of living, by its purely physical effect on the human temperament, would most beneficially influence the lot of mankind."

Freedom fighter Mahatma Gandhi said

"The greatness of a nation can be judged by the way its animals are treated."

We all think this world has to change. It has to be peaceful. How? If an individual himself is not peaceful in his thoughts, how come the world ruled by him can be peaceful? Human he is responsible for today's incidents. "As we sow, so we reap". Only we can clear the garbage we have deposited all these centuries. Only we have the power to clean up this mess. For that one needs to change the way he/she thinks. So if he/she changes his thoughts, there is a possibility for this world to change. Can we change our thoughts? Can we control them? Can we divert them on to the positive side? If asked the answer is "Yes". Through a process called meditation. In fact it is not a process but a state that a human goes through, by following a method/process.

How meditation is related to thoughts? Let's consider the understandings of different individuals about meditation \& its benefits.

Most of us are aware that doing meditation helps in mind relaxation, few got health benefits, good memory power, increased concentration, compassion towards all beings, few felt, probably experienced that meditation acts as a part in past life regression therapy. Some believe it answers life after death questions. Are these true? Obviously could be yes. When one does meditation, he would be peaceful $\&$ all his body organs are peaceful. No anxiety, no worry which are the vital source for a healthy physical body. One can get rid of BP, Sugar, heart attacks, and looks young when one is peaceful. So definitely meditation gives health benefits. Also when one is peaceful, the mind will be clear without junk thoughts \& in this less traffic of thoughts one can think widely about some solution he may need or some goal he may want to achieve. So it makes decision easy \& precise enough which makes him work very confidently. So this is how meditation builds up confidence.

\section{HARVARD PROOF OF MEDITATION BENEFITS}

Ref. [3], [4] the Harvard study observed that self-awareness and compassion regions of the brain grow larger through meditation, while the stress area shrinks.

Benefits of mediation can be beyond these. One can absolutely change/control/divert his thoughts with the help of meditation. It is logical. When an individual is peaceful definitely he will not think anything violent. There is no space for negative thoughts in him. There is no chance of violent desires towards anyone. He will absolutely be peaceful with what he has. At least for that time being. Similarly like how we land in a different state of mind when 
we watch a movie. Not only while watching the movie, it lasts for some more time after we come out of theaters.

If we continue meditation for more $\&$ more time, then we can be peaceful for more \& more time. It is somewhere telling or intimating us that we are in the present moment. Neither in the past to feel guilty about our bad happenings nor in the future to think about greedy. But now as we have power to be peaceful, we can have a glance at our past experiences so that we take a positive note on them $\&$ will be happy for our learning's.

Here is a toss. There could be uses of knowing about our past lives \& about our future through astrology \& other means. Does it in any way help us for a better now? Let's only consider now, this moment this life how to make it the best $\&$ the happiest one. For that we need to find a solution. How to get rid of all problems we are facing in this life \& turn it out to a celebration?

If every individual including our world leaders are peaceful, there will be no borders on this earth map, hence no wars. One starts working not only for him but for others as well which internally builds up trust on our fellow humans. Believe me guys we can change this world in to an eternally blissful planet just by changing our thoughts, with the strong intent.

\section{WAVESIN OUR BRAINS}

Neurons in our brain use electricity to communicate with each other. When millions of neurons communicate, large amount of electricity is produced. This is measured using EEG, Electroencephalography.

Neuro scientists say that there are 5 types of brainwave states which are emitted during this electrical activity. They are named as Alpha, Beta, Theta, Delta \& Gamma.

Each brain wave emit in its own frequency range which will be calculated based on cycles per second.

Today's common problem most of the humans facing is "Stress".

\section{A. Beta Waves}

Ref. [5] These waves are the brain state of waking consciousness. In this state, an individual will be in state of reasoning finding out logics. These are vital for effective functioning of a day. But, when this critical reasoning increases because of increase in beta wave frequency, it leads to stress, anxiety. So the less beta waves in our brain, the less stress \& anxiety.

\section{B. Alpha Waves}

Ref. [5] Alpha brain waves are emitted when we are relaxed both physically \& mentally. The brain learns at a faster and deeper level than it does in beta.

Still we will be aware of our surroundings.

When we are in alpha state, we put ourselves in the ideal condition to learn new information, keep fact, data, perform elaborate tasks, learn languages, and analyze complex situations.

When more alpha waves are emitted in a person i.e. when the alpha frequency range reaches a particular limit, he will be able to understand something immediately based on feelings rather than facts (intuition).

There is a renowned method called Silva method founded by Jose Silva which is being practiced by many people even today \& are benefited in their personal growth by increasing alpha waves. We have mentioned few testimonials of celebrities, who have followed the Silva method, at the end of the journal.

\section{Theta Waves}

Ref. [5] theta waves are emitted when we are in light sleep, where we have reduced consciousness.

\section{Delta Waves}

Ref. [5] delta waves are experienced in dreamless deep sleep, when there is no consciousness. Physical world awareness diminishes when we are in this state.

We produce lethargic behavior in this state. [6] Astral projection or Out of Body experience occurs in Delta.

\section{E. Gamma Waves}

Ref. [5], [7], [8] gamma waves are fastest frequency waves. People with high levels of gamma activity are exceptionally intelligent, compassionate, blissful, great memory power, richer sensory experience \& strong self-control.

Gamma brain waves are high in the left prefrontal cortex of the brain for meditation practitioners. This area is associated with decreased anxiety $\&$ fear, positive feelings.

Great achievers in diversified fields are said to produce more gamma waves.

If we take a great sports person like Sachin Tendulkar, he says he loves his cricket. When you love something you show all your intention, creativity, and love on it. One is immersed in what he loves. They have become great achievers in their field as gamma is a natural state of consciousness for them.

We can produce more gamma waves through meditation. Neuro scientists say that people can train themselves to produce gammawaves by practicing love \& compassion.

Tibetan Buddhist monks, Celestine nuns experimented \&observed that more gamma waves are produced during meditation. The activity of amygdala (brain's fight center) is greatly reduced \& the activity of left prefrontal cortex which is associated with self-control, happiness and compassion) increased significantly it seems. This suggests that meditation makes us a happier and more compassionate. [8] Brain Wave Chart (shows in Fig. 1).

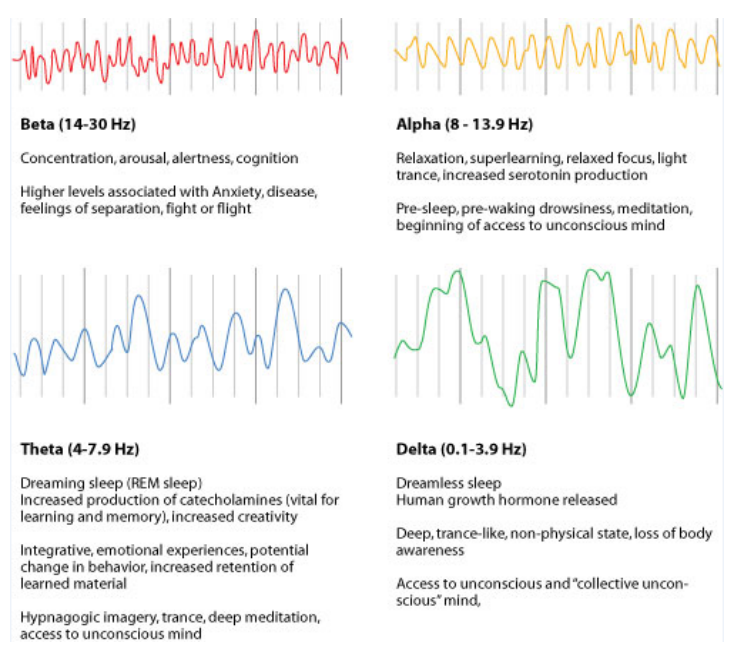

Fig. 1. Brain waves chart. 


\section{How to Meditate?}

\section{A. Ana Pana Sathi Meditation}

The word Ana PanaSathi comes from"Pali" language where 'Ana' means inhale of breath, 'Apana' means exhale of breath \& 'Sathi' means 'be-one-with'.

Take any comfortable sitting posture. Clasp your hands $\&$ close your eyes. Observe the natural flow of the breath. We need to observe how we are inhaling $\&$ how we are exhaling. This continuous process needs to be observed. When we are getting carried away by the thoughts we need to bring our attention back to the natural flow of breath.

Do not chant any mantra \&do not entertain any form of deity in the mind. Do not perform pranayama practices.

When we are with the breath-energy, the mind becomes rather empty. Then, there is a tremendous in-flow of cosmic energy into the physical body. Gradually, the hitherto dormant third-eye becomes activated. And, by and by, cosmic consciousness is experienced.

\section{CONCLUSION}

If every individual including our world leaders are peaceful, there will be no borders on this earth map, hence no wars. One starts working not only for him but for others as well which internally builds up trust on our fellow humans. Believe me guys we can change this world in to an eternally blissful planet just by changing our thoughts, with the strong intent.

Doing meditation helps us in directing our thoughts on to the positive, peaceful side. More $\&$ more gamma waves are emitted when we are in the state of meditation.

Plant based food is a catalyst to this. As there is no violence in our food, we are peaceful in our thoughts.

When thoughts are peaceful, no pride, no greed, no fear, no ignorance $\&$ no desire.... hence only love exists.

Finally, the planet earth is peaceful.

VIII. World FAMOUS PEOPle ABout Meditation IN THEIR WORDS (EXCERPTED FROM DIFFERENT SOURCES OF WEB LIKE WIKIPEDIA, TMHOME.COM)

If you want to live a more fulfilled life, first you will want to know your potential, what you really are. Meditation is the route to that knowing. It is the methodology of the science of awareness. - OSHO

"I'm quite a neurotic thinker, quite an adrenalized person. But after meditation, I felt this beautiful serenity and selfless connection." - Russell Brand (A vegetarian)

"If you just sit and observe, you will see how restless your mind is. If you try to calm it, it only makes it worse, but over time it does calm, and when it does, there's room to hear more subtle things - that's when your intuition starts to blossom and you start to see things more clearly and be in the present more. Your mind just slows down, and you see a tremendous expanse in the moment. You see so much more than you could see before. It's a discipline; you have to practice it." Steve Jobs

"Meditation is all about the pursuit of nothingness. It's like the ultimate rest. It's better than the best sleep you've ever had. It's a quieting of the mind. It sharpens everything, especially your appreciation of your surroundings. It keeps life fresh." Hugh Jackman

Dr. Mehmet $\mathrm{Oz}$ is a practitioner of Transcendental Meditation. "When I meditate, I go to that place where truth lives", he said. "I can see what reality really is, and it is so much easier to form good relationships then." (Source Wikipedia)

"When we are with the breath-energy, the mind becomes rather empty. Then, there is a tremendous in-flow of cosmic energy into the physical body. Gradually, the hitherto dormant third-eye becomes activated. And, by and by, cosmic consciousness is experienced. "- Brahmarshi Subhash Patriji

Gillian Anderson - "I mean the whole thing about meditation and yoga is about connecting to the higher part of yourself, and then seeing that every living thing is connected in some way."

"Meditation is a lifelong gift. It's something you can call on at any time. I think it's a great thing." - Paul McCartney (Musician, Singer)

"I have been practicing the Transcendental Meditation technique for over 30 years. Transcendental Meditation has helped me to consistently raise my performance levels. It has helped me cope with the stresses and strains of life. And I believe very strongly that the practice of meditation has helped me to maintain a steady state of mind - it has given me equanimity no matter what happens." - Ramani Ayer (b. 1947) is a business executive, former CEO of the Fortune 500 company The Hartford.

\section{FeW EXPERIENCES OF Who Practiced Silva Method}

Ref. [9], [10], in 2010, Mark Robert Waldman, the world-famous neuroscientist and bestselling author of How God Changes Your Brain said.

"Based on the newest findings from Harvard's recent genetic study on the effects of relaxation, breathing awareness, and positive guided imagery, I feel confident that many of the methods, as taught by Silva International, can stimulate gene expression in the brain that is involved in reducing physical and psychological stress and boosting immune functioning."

\section{A. Businesses}

Robert Stiller, the CEO of Green Mountain Coffee, says "Silva demonstrates that there is no limit to what the mind can do "Many top-shelf corporations, including RCA Records, Green Mountain Coffee and The Arnold Agency, have sent their employees for Silva training.

Benefits have been reported in various areas, including amplified creativity, improved business management, enhanced motivation and better stress management.

\section{B. Sports}

Russell "Bucky" Dent, a baseball player with the Chicago White Sox, began studying the Silva Method in 1975. In 1978 he was named Most Valuable Player at the World Series. Dent has been quoted as saying, "The Silva Method helped 
me with my concentration, and it helped me to relax before the pressures of a game." To this day, many world-class athletes use the principles of The Silva Method to visualize their desired outcomes, improve focus and keep their minds and bodies in optimal condition. Silva has an especially huge following in sports that encourage a mind-body approach to physical excellence.

\section{Well-Being}

Many healthcare professionals and scientists have integrated the principles of The Silva Method into their healing regimens as a crucial component of effective mind-body healing. Dr. O Carl Simonton, founder of the Simonton Research Institute, which practices and researches imagery therapy for patients, calls The Silva Method one of "the most powerful single tools that I have to offer patients." Professor Clancy D. McKenzie, founder of the American Mental Health Association, is also known to have used Silva techniques to aid his patients.

\section{REFERENCES}

[1] J. Cross, Fat, Sick and Nearly Dead, Joel Fuhrman (Foreword), Dean Ornish (Afterword).

[2] S. Chinmoy, World-Destruction: Never, Impossible! Part 2, Agni Press, 1994.

[3] Mindfulness Meditation Practice Changes the Brain. (April 2011). [Online].

Available: http://soschicagoland.com/2011/05/14/benefits-of-meditation-harvard -study-provides-more-proof/

[4] L. Salahi and C. Cole, "Meditation prescribed more often as alternative to conventional medicine," Study Finds Video - World News.
[5] C. W. MSc, Gamma Healing: Eliminate Subconscious Limiting Beliefs, Anxiety Fear And Doubt In Less Than 5 Minutes.

[6] L. Darmosz, Brain Waves-Metaphysical Soul Massage.

[7] The Marvelous Properties of Gamma Brain Waves, April 15, 2012.

[8] B. Phillips, Where Science Meets Spirit: The Formula for Miracles.

[9] The New York Times. (April 16, 1972). Paper Topic-Can man control his mind? [Online]. Available: http://www.silvalifesystem.com/lpv?hot_id=10249205102224713100 5\#sthash.5Ptxcp21.dpbs

[10] J. Silva, The Silva Method.

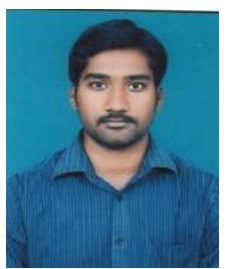

J. V. Manoj is based out of India. He obtained bachelor's degree in computer science from Anna University, India in 2008.

He works as a software engineer in one of the multinational companies at Hyderabad, India. He is an active participant in spreading meditation through PSS movement organization http://www.pssmovement.org/. He believes that meditation is the key to success \&it is a new experience, a joyous, an unfolding, a new learning, a new perception of the world. Lalithendra Nadh is from India. He earned his master's degree in information technology from Vignan University, India in 2011

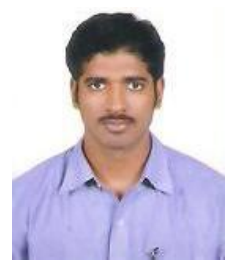

V. Lalithendra Nadh is working as an assistant professor in one of the Engineering Colleges at Vijayawada, India

He believes that meditation is all about the pursuit of nothingness which he has been experiencing in his own personal experiments.

Mr. Lalithendra is an active participant in spreading meditation through PSS movement organization http://www.pssmovement.org/

He has given many extemporaneous talks on meditation to public, at colleges, sub-jails etc. 